\title{
New developments of the project Learning by Research
}

\section{Manuel Costa}

Manuel Filipe M. Costa, "New developments of the project Learning by Research," Proc. SPIE 3831, Sixth International Conference on Education and Training in Optics and Photonics, (16 June 2000); doi:

10.1117/12.388703 


\title{
New developments of the project "Learning by research"
}

\author{
Manuel F. M. Costa \\ Universidade do Minho, Departamento de Física \\ Tel. +351 53 604334(/20); Fax.+35153678981; Email: mfcosta@fisica.uminho.pt \\ P-4719 BRAGA CODEX \\ PORTUGAL
}

\begin{abstract}
In this communication we will present new results and developments of a pedagogical experiment undertaken, since 1995, within the classes of Image Processing and Fiber Optics of the Applied Physics undergraduate course of the Physics Department of the University of Minho. The simple research works undertaken by the students within the classes' frame over last three years will be briefly discussed and preliminary conclusion drawn. This "Learning by research" project relies on a major statement: the learning process requires always an active critical participation of the students. This is especially true for science and technology students. Thus to the students is given almost entire liberty and responsibility even in the process of choosing and defining the research to be undertaken. We limited our selves to assess the development of the project orienting them and point out different or pertinent points of view when strictly necessary.
\end{abstract}

\section{INTRODUCTION}

The learning process demands always an active participation of the students. However this is not always easy to achieve. And unfortunately this is every day a more acute problem. There's a wide range of problems affecting undergraduate science and engineering teaching at the university that are, generally, well characterized and recognized by the different counterparts involved. However the points of view on these issues may differ. Apart from the point of view of the community, that in the end should define and assess the teaching quality requirements and requirements' tolerances, three contributions are of major importance: the point of view of the university it self; the teachers; and the students. Not only the diagnostic but also the proposed solutions by the different parts do essentially coincide.

The university needs to give a positive answer to society demands. Not always these are clearly stated or stable. Especially with the industry the interaction is not always easy. Keeping a high quality teaching standard becomes extremely demanding in financial terms. It is permanently necessary the scientific and pedagogical actualization of educators and support staff, the replacement and improvement of laboratories and equipment for pedagogical support in order to cope with the rapidly changing requirements. Another important problem facing the university is the numerus clausus and the obligation of preparing in quantity and due time students upon the market needs and political determinations.

From the point of view of the teacher apart of the evidence of a social and professional depreciated position, the main problems come from the work conditions: in terms of work load; pedagogical and scientific actualization conditions; deficiencies in the laboratories and support pedagogical equipment and staff; but also the student's behavior in general terms ${ }^{(1)}$. At this level the low high school preparation especially in mathematics and Portuguese is a basic major constraint. Major difficulties of communication (either in terms of oral, written or plastic expression or comprehension) are noticed at alarming levels. Important is also to notice that this is recognized by the majority of student as the major constraint to the development of their studies. We have made in 1995 an informal inquest ${ }^{(1)}$ on students' opinions about the quality of the course, and their own performance and expectations. Statements produced here about students' point of view take into account the inquest's results.

The lack of motivation is another major issue justified by the students (eventually not deeply enough) by social distress and absence of perspectives for the future (employment, security...). The need of hard work is definitely difficult to 
accept by the students. They tend to act very passively. No sense of enjoying learning is the norm. Easy but above all fast unquestionable solutions are expected and demanded. An informal inquest made a few years ago with our students shown that over $80 \%$ of our students think that the clear explanation, by the teacher, of the subjects is by far more important than their own participation on the analysis of questions and problems. That's surely of utmost importance, but... Moreover the students think the teacher should not expect or demand an active participation of the students on class. Nevertheless, it is exactly on the opposite direction we (teachers) should focus our efforts: encouraging or even demanding an active permanent participation of the students; trying to develop their sense of observation (seeing critically) and critical reasoning by performing more experimental work and bringing to discussion real life issues (an extreme caution must to be taken here to stress clearly the limitations of our often simplified approaches); demanding hard work and stimulating the sharing of ideas (communication). Trying to make the students to be predisposed to have fun in class it's rather important. Although not always easy to implements this is an effort that may give a good result's improvement.

But we also should never forget teaching takes time. Learning takes much more. Increasing students' specific knowledge is important. But above all science demands work, responsibility and method. It is precisely this we science teaching should give to the students. Perhaps more important than knowing concepts or theories is to know how to get them. It's necessary to think, to reason, to analyze critically and interactively problems and situations. More important then the final concepts, is to know, feeling, to interiorize the paths or processes of, or to, understand them.

For long time it is my believe that the development, by the students, of, even if simple and straightforward, research works in either fundamental or applied subjects is a wonderful way of guarantee a true sound and durable true understanding of the topics we teach. Furthermore the experience gained will be of utmost importance for the students future professional life.

\section{TEACHING BY RESEARCH}

On next paragraphs we will briefly present a series of small research works my students of the classes of Fiber Optics and of Image Processing developed during the last four years.

\subsection{INTRODUCTION}

At the second semester of the academic year of 1995/96 I had in my class of Image Processing ${ }^{(1,5)}$ I shought I gatter the ideal conditions to begin my pedagogical experiment "Learning by research". In fact I first call it "Teaching by research" but soon agreed that I should emphasize right from the beginning that what realy matters is the students' learning "by them selves". Elsewhere ${ }^{()}$detailed description of this first research work was presented. Briefly I can summarize it saying that the work toke place during the classes of Image Processing in 1995/96 and was done by an homogeneous group of four students. It consisted on the development of an image digitalization and processing system able to measure, in an automated way, the lateral position of small cubic boxes falling erratically over a conveyer belt.

As I said above this pedagogical experiment was undergone in two different classes of the final year of the Applied Physics (Optics and Lasers branch): Fiber Optics and Image Processing during the first and the second semester respectively. They indeed involve different types of subjects and different types of class organization are needed. However the development of the classes followed a scheme similar of that chosen for the first year of the experiment. Then I divided the 14 weeks of the course in three parts. In the first six weeks several lectures were made introducing all the basic subjects involved in the theme of image characterization, acquisition and digitalization, and digital image processing techniques. Practical examples were frequently introduced.

Four practical works were done at the laboratory taking around 12 hours. Different software was used to make the students work and learn all the major image processing operators applied on the images the students them self chose and digitized. At the end of this period the students knew the essential of all available hardware and software equipment available. Then three practical problems were presented to the students: early detection of skin cancer by the detection of skin signs its characterization (size, shape, roughness, color distribution...), storage and automated comparison with previous acquired images of the same marks; distance measures using video cameras and image processing; cars' speed measures by image acquisition, digitalization and treatment.

During two weeks they discuss the possible solutions to each one of them. The process was freeze for a while and the main problem/project was defined.

The problem was specified as follows: in one conveyor belt running at a fixed low velocity, are dropped, at a known low frequency, small cubic boxes. The boxes fall always with faces aligned with the belt, but at different, erratic, transversal distances from the sides of the conveyor belt. The method to be developed should deal with the determination of that lateral position. During over five weeks the student used each one of the six hours per week (and surely some more...) trying to understand and solve the problem. At the end one full extended week was enough to settle all the fundamental image processing issues in a systematic way. 


\subsection{A BRIEF PRESENTATION OF SOME OF THE WORKS DEVELOPED OVER LAST FOUR YEARS}

Not always the established goals were achieved. Some of the projects were non-laboratorial in essence. In any case the results had always a positive budget. To the students was given almost entire liberty and responsibility to develop their work but also to chose the topic and define the research to be undertaken. Even when the students chose one of the themes I proposed they had to, by them selves, specify and define the research process to be developed.

Next a brief description of the different projects developed is made.

- Mid range distance measurement by defocus and depth of focus control. The idea was to use a conventional semiprofessional CCD camcorder with image digitalization and processing to locate objects at different distances from the camera by controlling its zoom and depth of focus. The work was successfully performed by a group of four students and the resolution and accuracy for distance measurement in different ranges above 1.2 meters, were determined.

- Fiber optics endoscope for dentistry. The work was performed by a group of two elements and the objective was to project one video endoscope for use in dentistry. A coherent fiber bundle with 32000 fibers, NA and mm diameter from was considered. Grin lenses for and operation distance of $6 \mathrm{~mm}$ and the output end of the fiber should be coupled by a $\mathrm{b} / \mathrm{w} 1 / 42$ ' CCD OEM camera. Both imaging systems were calculated and partially tested. The endoscope was sketched but not implemented.

- Skin cancer early diagnoses by image acquisition and processing. The work was performed by a group of four students with, at some point, cooperation of a group dealing with fringe projection. The medical aspects of cancerigenous melanomas were first studied focusing in the visual early diagnostic methods. The cooperation of the Hospital of the University of Coimbra is acknowledged. After definition of the visual relevant characteristics of the images to be acquired of skin marks, a set of images were acquired using a macro lenses and a b/w (Electrim's EDC$1000 \mathrm{HR}$ ) and a Cohu, 2000 series, color camera. A image processing strategy was established and partially implemented. Below are shown a few examples (some done by other students in later years).

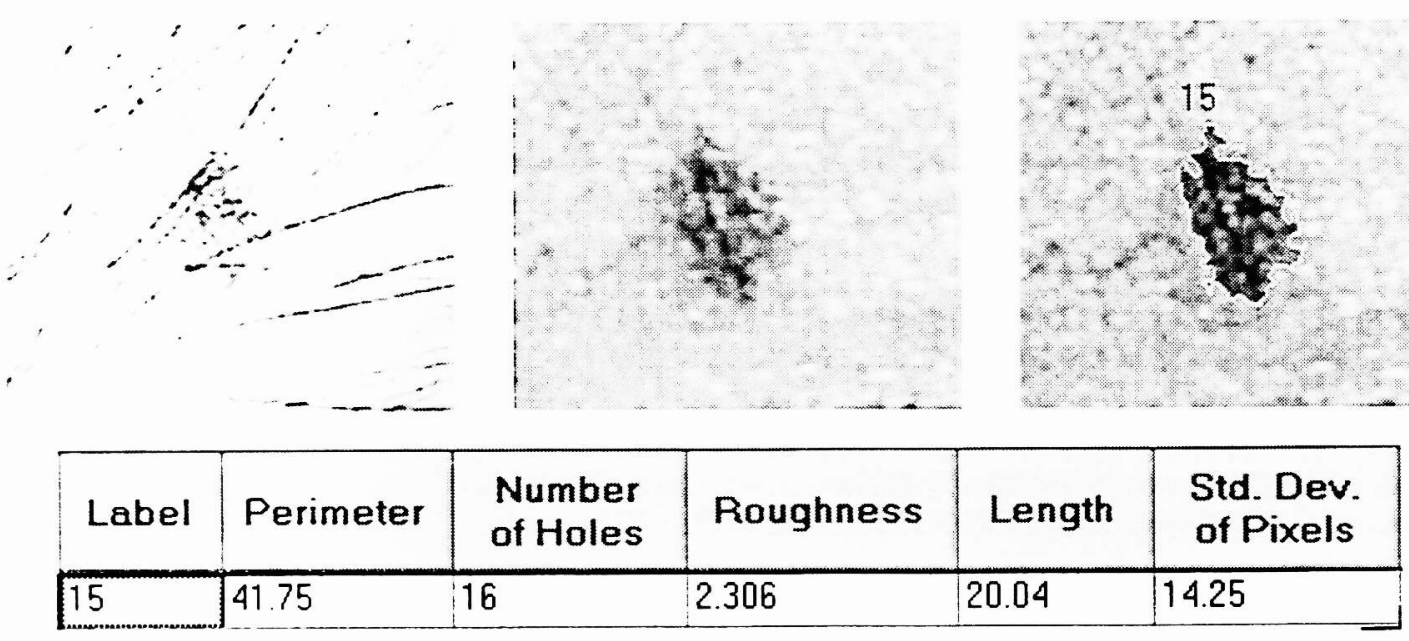

Figure 1. A common healthy skin mark. The blob analysis is performed (distance measures in $\mathrm{mm}$ ). However previous image processing is needed in order to remove the superimposed hair. An erosion and diagonal averaging filters was applied.
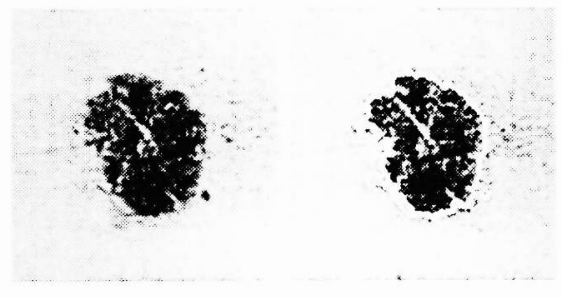

\begin{tabular}{|l|l|l|l|l|l|l|} 
Label & Area & Perimeter & $\begin{array}{l}\text { Number } \\
\text { of Holes }\end{array}$ & Roughness & Length & $\begin{array}{l}\text { Std. Dev. } \\
\text { of Pixels }\end{array}$ \\
\hline 9 & 17.23 & 29.98 & 15 & 1.847 & 13.73 & 16.61 \\
\hline 13 & 0.1 & 1.283 & 0 & 1.068 & 0.3741 & 12.25 \\
\hline
\end{tabular}

Figure 2. Some of the skin marks have a pronounced relief. 

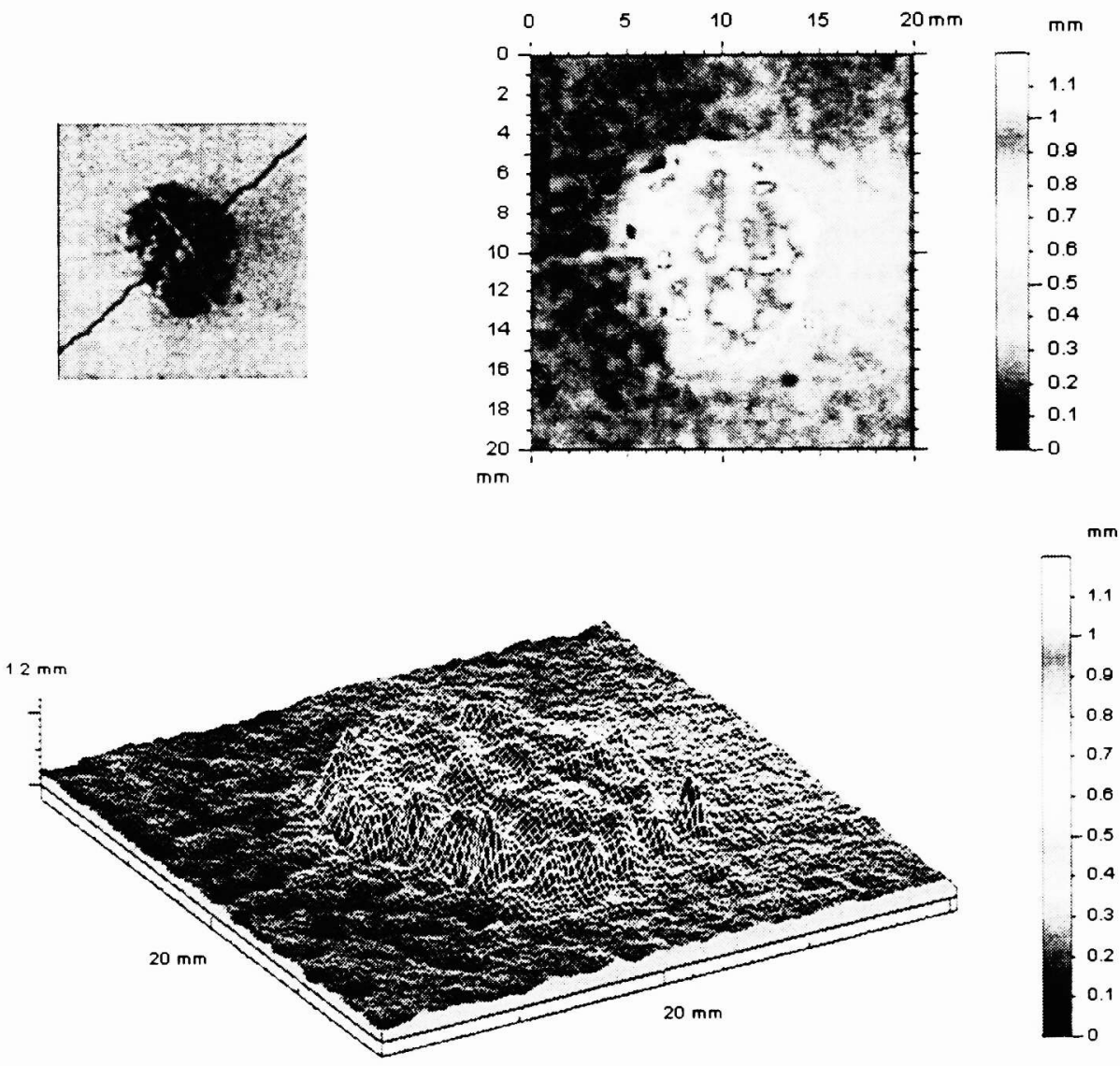

Figure 3. By fringe projection the topography of the skin mark can measured and reproduced with vertical and lateral resolution of some microns ( 10 and 50 microns respectively).

- Displacement fiber optic sensor. A simple fiber optics sensor was assembled to measure small submilimeter displacements of mirror like surface. A cone of light is projected onto the surface, placed perpendicularly to the fiber tip, and the amount of reflected light collected by the same fiber is measured. This work was considered a good lab for consolidation of the basic concepts of fiber optics systems.

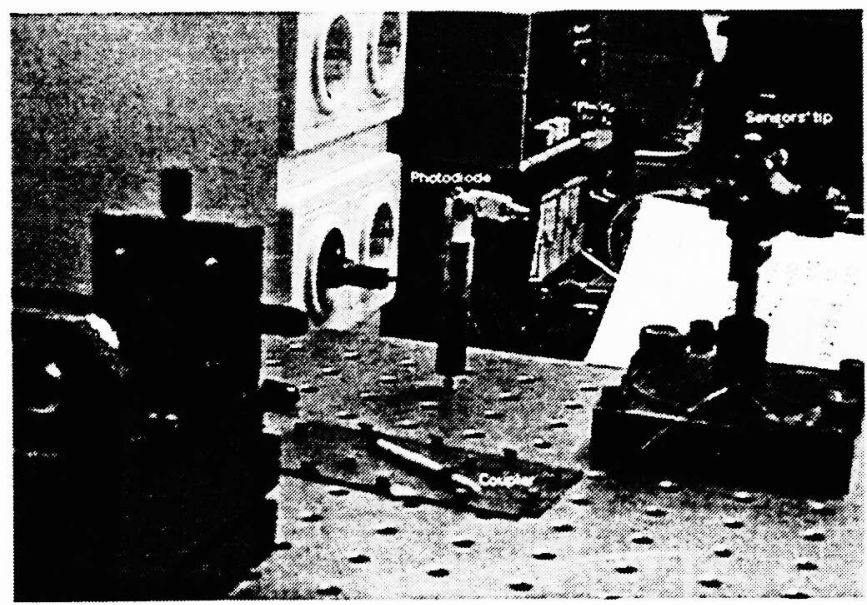

Figure 4. A view of the setup of the displacement fiber optic sensor developed. 
- Fringe projection. A simple setup including and HeNe laser, two interchangeable cylindrical lenses and a CCD camera connected to a microcomputer by a digitizer video blaster SE100, was assembled. Allows the 3D inspection of objects by fringe projection and optical triangulation. Manual lateral scanning is performed however a step motor driven stage was also used. Dynamic ranges from 1:200 to 1:1000 were achieved.

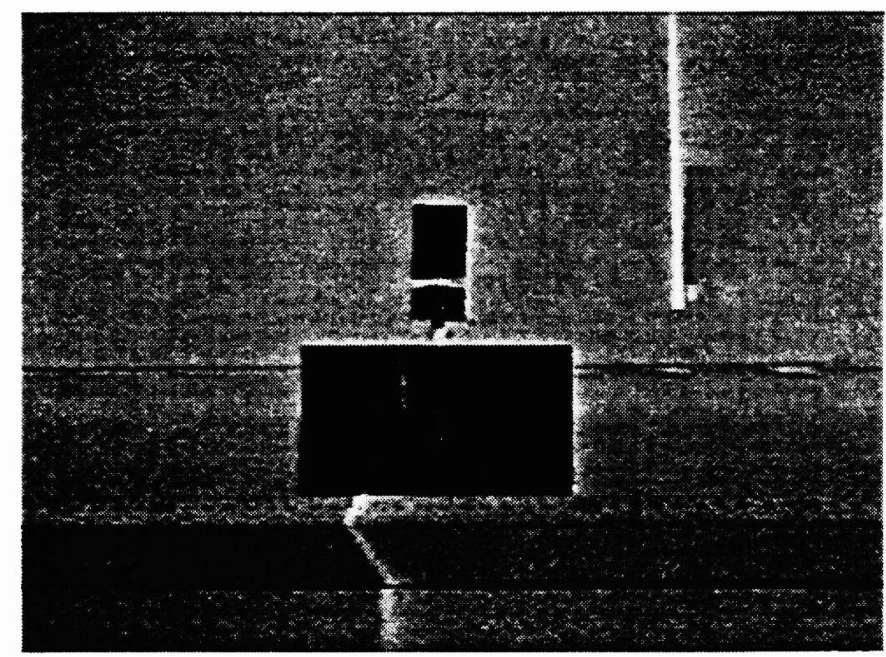

Figure 5. Fringe projection at 3 to 3.3 meters distance.

- Velocity measurement by image acquisition and processing. Again using the available material and image processing techniques the students should established a method to measure velocities. They, a group of three students, chose the velocity range to be dealt with, assemble and calibrated the system. The raster of the image that depends on the cameras" integration time allows them to evaluate the velocity of the object by measuring the amount of "spreading" on the objects' image. Large errors (above 15\%) were presented especially for higher velocities however the work was a good experience allowing the students to understand more deeply the way cameras work.
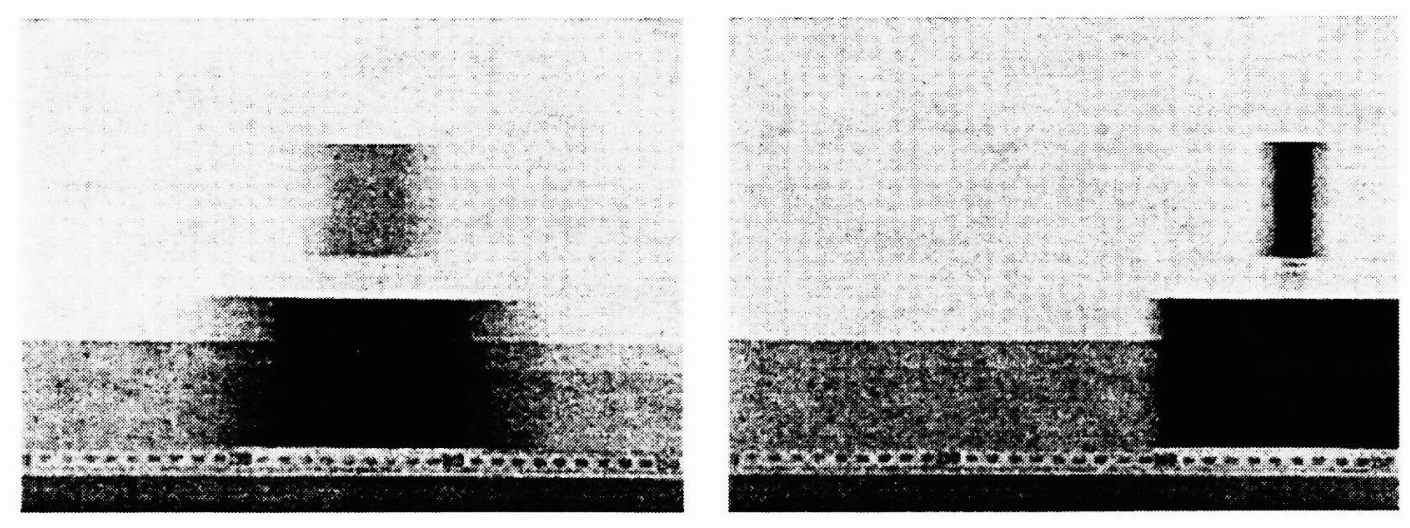

Figure 6. The acquired images for the object moving at different velocities.

- Electric voltage measurement using fiber optics. A theoretical analysis of the possibilities of measuring electrical voltages using fiber optics and fiber optics' sensors was performed with good quality by two students.

- Pattern matching in fabrics production. We shall refer to this work with some detail in another communication (3831-113).

- Depth from triangulation and shadowing. This work was detailed presented elsewhere ${ }^{(8)}$. Next we will just summarize it briefly. A group of four students were asked to develop a method for assessing the lateral position of 0.1 meters large' cubic boxes dropped at a known frequency into one 0.45 meters wide conveyor belt running at a fixed low speed. The boxes fall always with faces aligned with the belt, but at different, erratic, transversal distances from the sides of the conveyor belt. Optical triangulation ${ }^{(9)}$ was suggested as the basis for the method that also should integrate 2D image' data processing and feature's detection with subpixel resolution. In order to study the best possible 
resolution the system can give, no movement should be involved. No conveyor belt movement is present. The box is displaced laterally, perpendicularly to the conveyor belt's movement direction. The lateral position is closely controlled by the employment of a precision linear displacement stage. The students have to realize the importance of the influence of the movement and all other practical implementation constraints on the system's resolution, accuracy and reliability.

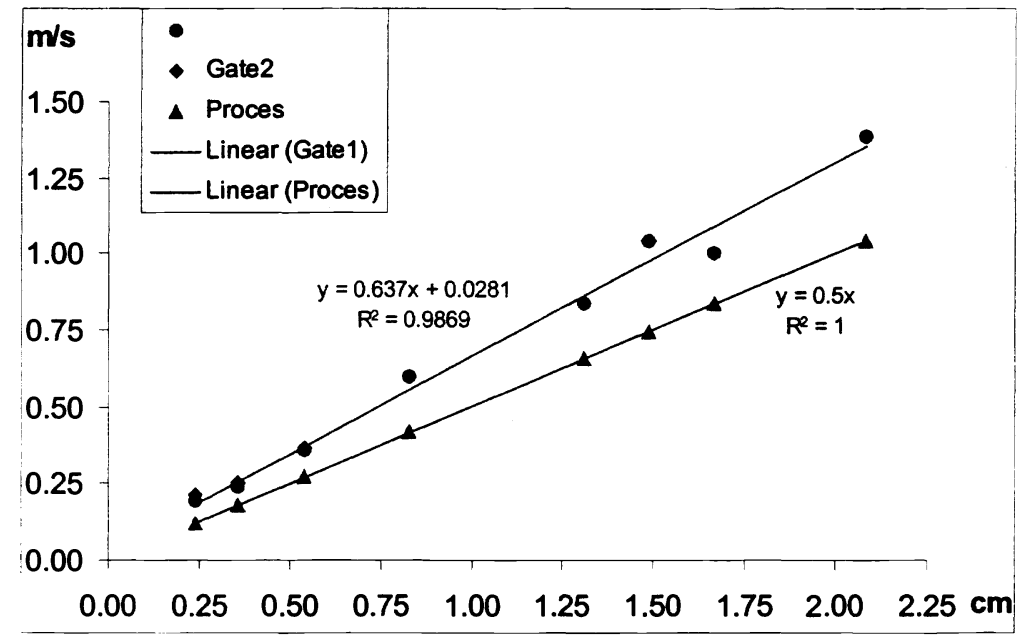

Figure 7. The calibration curve. The experimental point above are the data obtained by and electronic velocity measurement apparatus from Pasco and bellow ours students' setup results.

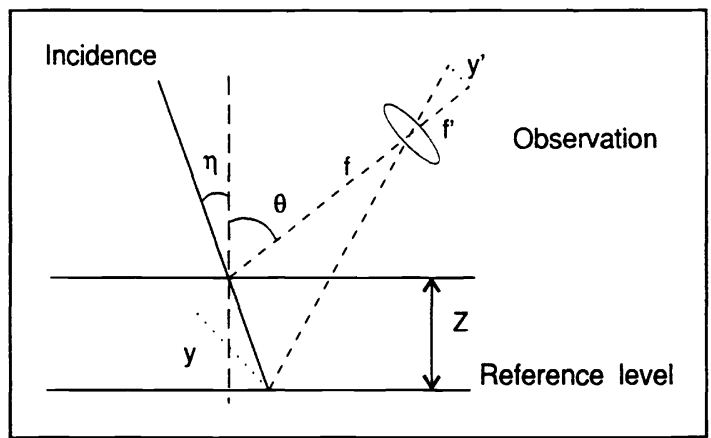

Figure 8. The general triangulation geometry:

$$
y^{\prime}=M \frac{Z \sin (\eta+\theta)}{\cos \eta+(Z / f) \cot (\eta+\theta)}
$$

where $M=f / f$ is the optical magnification in the observation arm, $f$ and $f$ are the focal lengths of the observation optics, $\eta$ the incidence angle and $\theta$ the observation one.

Several system's configurations were considered. In Figure 9. is presented the relation between the shadow's edge location on the camera's sensor plane and the distance from the point source to the target. Experimental data is plotted (dots) over the theoretical curve for a box depth of $h=20 \mathrm{~cm}$. The relation between the shadow's edge location and $d$ is linear. Unfortunately the relation between the measured quantity $x$ and box's position or depth, $h$, is not linear. If we decided to use a light source placed far apart from the conveyor belt the ray illuminating the scene will be parallel and the conversion relation ( $x$ to $h$ ) will be simple and linear (ignoring aberrations, misalignments and non uniformity at the sensor). Nevertheless keeping all hardware closer will certainly be more convenient. Thus the choice of a point like source was clear. On view of the problem' constraints and camera's characteristics we decided to make $L=56.5 \mathrm{~cm}, \mathrm{~d}=9.00 \mathrm{~cm}$ and $b=40 \mathrm{~cm}$. Thus $x_{\min }=1.974 \mathrm{~cm}$ and $x_{\max }=35.217 \mathrm{~cm}$. The displacement of the box's shadow edge between the extreme positions in the conveyor belt will roughly correspond on the detector plane to almost a 500 pixel's shift of the image's 
shadow edge location. This means that virtually the whole available sensing camera's area will be used thus allowing the best resolution.

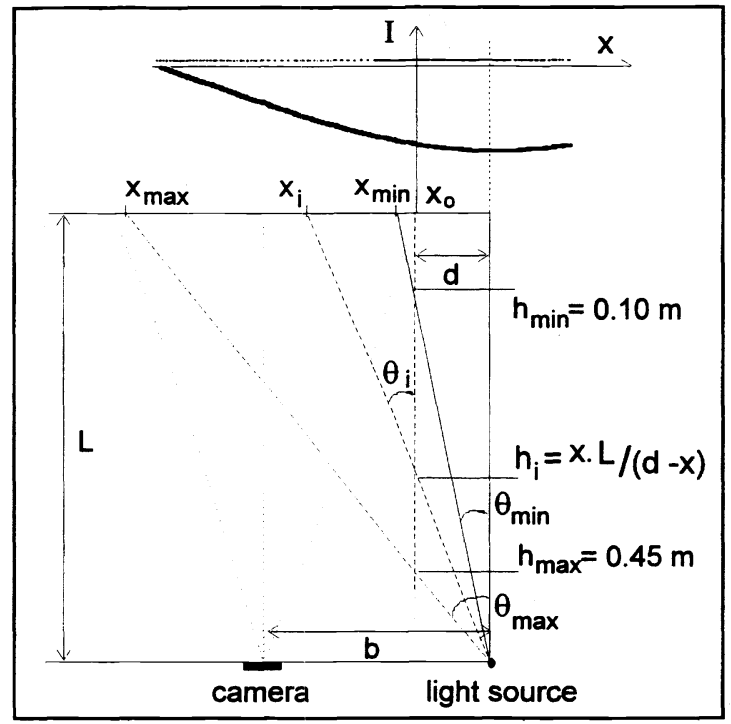

Figure 9. The measurement procedure.

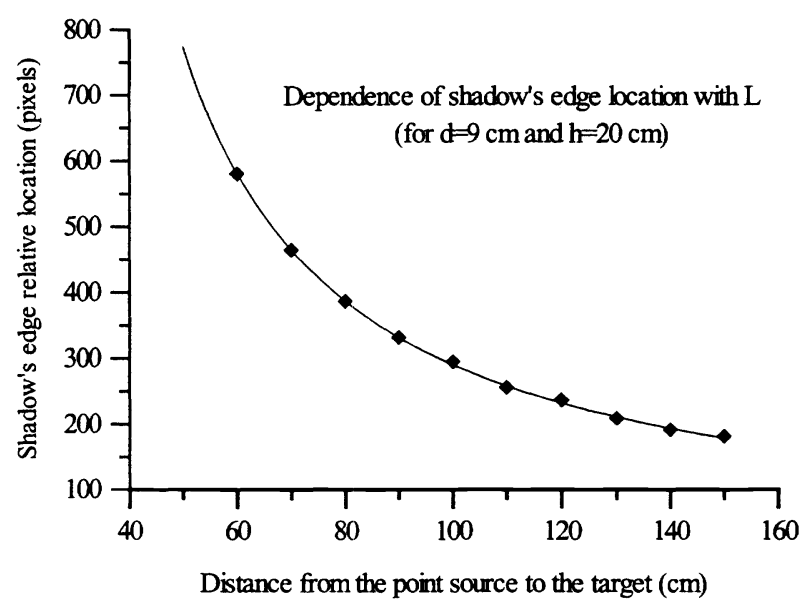

Figure 10. Shadow's edge location versus $\mathrm{L}$.

The light source used is a simple $20 \mathrm{~W}$ bulb. The CCD camera is an Electrim's EDC-1000HR b/w camera supplied with a "frame-grabber" computer interface card. The sensor with $753 \times 244$ (488 interlaced) pixels have a sensing area of $8.67 \times 6.59 \mathrm{~mm}^{2}$. The exposure time can be controlled from $10 \mathrm{sec}$. down to $1 \mathrm{msec}$. The objective used is a Computar of 8.5 $\mathrm{mm}, 1: 1.5$ and $2 / 3$ " diameter. The system presents some aberrations including barrel distortion. Thus we set the system in such a way that the pixels on the extreme areas of the sensor are not used. Nevertheless the calibration procedure can deal with these problems in large extent. Below calibration curves are presented.

\section{CONCLUSION}

The process of teaching science and engineering should be essentially practical. The contact with the analysis and solution of specific practical, simulated or real life, problems is in this context fundamental. In what concerns the basics of optical fibers and systems, and image processing this definitely true. Furthermore the strongly interdisciplinary of this, and 
most of the others, themes should stressed. Apart from a good knowledge of the fundamental issues it is necessary a deep understanding of the, in this case physical, problems and processes involved in the wider range of situations.

The students should also to be aware of the specific constraints and requirements presented by the real world.

From the pedagogical point of view it is my firm opinion that the project gave excellent results. Not only in the learning of the fundamental and major concepts, but specially on the students' character building. They do realize the importance of reliability and responsibility, and improved their work method gaining self-confidence and self-esteem.

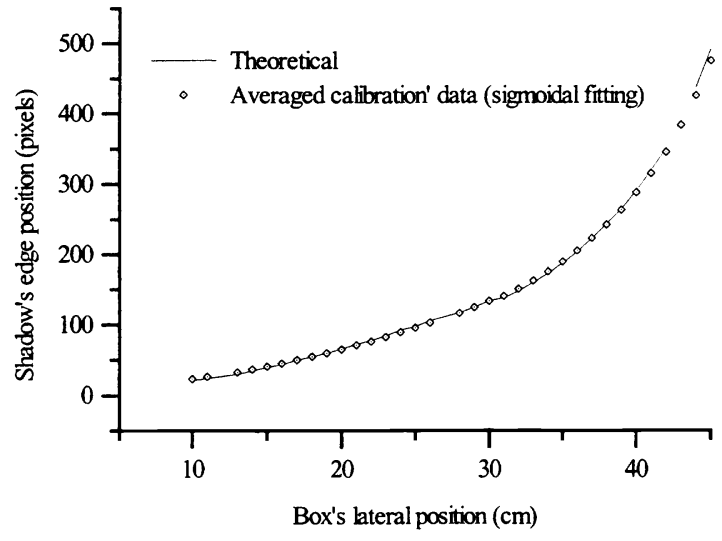

Figure 11. The accepted system's calibration curve.

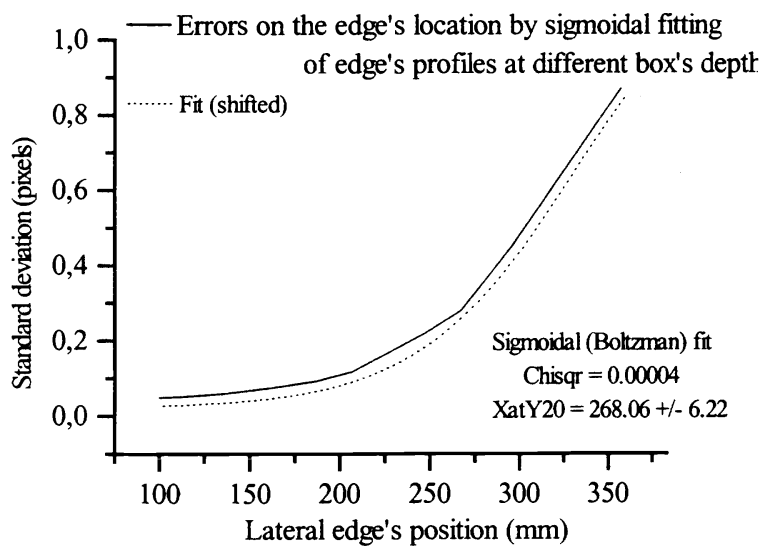

Figure 12. The calibration errors.

\section{ACKNOWLEDGMENT}

For their work and support in this project the author wish to express his acknowledgment to Mr. Jorge, Faria, Carvalho, Las Casas, Fernandes, Moreno, Dias, Mota, Pinto, Peixoto, Trocado, Ferreira, Reis, Tavares, Francisco, Castro, Guedes, Lopes and Rodrigues, undergraduate or former undergraduate students of the course (licenciatura) of Applied Physics (specialization in Optics and Lasers) of the Physics Department of the University Of Minho.

\section{REFERENCES}

1. Manuel F.M. Costa, “Teaching Applied Optics at The University of Minho", Proc. Soc. Photo-Opt. Instrum. Eng. 2525, 357-361 (1995).

2. P. Narayana Swany; "Put the real world in the physics curriculum", letter, Physics Today, vol. 48, n. 9, p. 15 (1995).

3. A. S. Prasanis; "Teaching Optics in the Optics Age", Proc. Soc. Photo-Opt. Instrum. Eng. 2525, 318-330 (1995).

4. Shoang C Donn; "Optics Education for Now and Future from an Entropy Perspective", Proc. Soc. Photo-Opt. Instrum. Eng. 2525, 497-507 (1995).

5. Introdução ao processamento de imagem, Manuel F.M. Costa, Universidade do Minho, 1995.

6. Digital Image Processing, W. K. Pratt, John Wiley \& Sons, 1978.

7. Microtopografia laser, Manuel F.M. Costa, Universidade do Minho, 1993.

8. Manuel F. M. Costa, Rui Las Casas; "Depth from triangulation and shadowing", in Proceedings of the International Conference on Pattern Recognition RECPAD’96, 367-372 (1996).

9. Manuel F.M. Costa, J.B. Almeida; "System of optical noncontact microtopography", Applied Optics, vol. 32, no. 25, 4860-4863 (1993).

10. Manuel F.M. Costa, “Surface Inspection by an Optical Triangulation Method”, Opt. Eng. 35(9) 2743-2747 (1996)

11. R. A. Brook, "Automatic inspection in industry today", in Proceedings of the International Conference on Industrial Inspection, D. W. Braggins, ed., Proc. Soc. Photo-Opt. Instrum. Eng. 1010, 2-7 (1988). 